\title{
The Protective Effect of Non-fluoroquinolones against Chemo- and Radiation Therapy- Induced Damage in Mice
}

\section{S. F. Ahmed and M. A. Abd-El-Rahman*}

Health Radiation Research Dept., National Centre for Radiation Research and Technology (NCRRT), P. O. Box; 29 Nasr City, Egypt and "Chemistry Dept., Faculty of Education, Ain Shams University, Cairo, Egypt.

\footnotetext{
CANCERS of head \& neck has increased in the last years with increased use of chemo-radiotherapy. So, the trials to achieve newly developed agents that combat the hazards of cancer therapy have been urgent. This study was carried out to investigate the possible protective effect of new quinolone derivative against the oxidative damage of chemo-radiotherapy. Twenty four male mice were divided into four groups; group $\mathrm{C}$, mice were served as control, group SR, mice were injected with cisplatin for 5 days and then irradiated with 2 Gy at the last day, group QSR, mice were injected with non-fluoroquinolone; 2-(1-Ethyl-4-hydroxy-2-oxo1,2-dihydroquinolin-3-yl)-2-oxoacetic acid (EHQA) for 14 days in addition to injection with cisplatin in the last 5days then irradiated, group Q, mice were injected with EHQA for 14 days.

Tongue specimen was subjected to histological and immunehisto-chemical evaluation for proliferative and apoptotic activity. Histologically, EHQA administration prior to cisplatin and radiation exposure ameliorated the damaging effects of both on tongue. Morphometric studies of the treated group represented marked increase in proliferative and anti-apoptotic capacity of the epithelial cells especially the basal cells. Administration of EHQA before chemo-radiotherapy can to great extent, reduce the hazardous effects and the mechanism by which exerted its effect can be related to regulation of cell cycle and cell death processes. Key words: Cisplatin, $\gamma$-rays, quinolone, tongue, Mice.
}

One third to one half of patients with head and neck cancer requires radiotherapy during some point in their clinical management (Baliga and Rao, 2010). Radiotherapy may be used as a single modality or as an adjuvant along with surgery and/ or chemotherapy (Hogle, 2007). Radiation-induced injury to surrounding normal tissues restricts the delivery of the effective dose to tumours that may reduce compromise treatment efficiency (Hosseinimehr, 2007). 
Tongue is one of the most affected organs by deleterious effect of radiotherapy, it causes degeneration, atrophy and collapse of the fungiform papillae and taste buds that reached its maximum within 10-20 days but recovered partially as some atrophied papillae and buds persist up to 60 days (Chen et al., 2004). Post-irradiation, the loss of taste sensation can be attributed to loss of taste cell combined with temporary arrest of cell replacement (Nguyen et al., 2012). In addition, chemotherapy caused direct damage of mucous membranes of oral cavity especially the basal cell layer end with loss of renewal capacity followed by cell death, mucosal atrophy, collagen degeneration and ulceration (Treister and Sonis, 2007).

Cisplatin; chemotherapeutic drug in combined use with irradiation enhanced its damaging effect inducing more sever lingual ulcer (Cotrim et al., 2012). The actual mechanism by which cisplatin exerted its effect is not fully understood. Many authors said that the action of cisplatin is cell cycle-independent, although in some cases; prolonged G2 phase cell-cycle arrest occurs (Siddik, 2003). Others stated that cisplatin-induced cell death is thought to arise from cross-linking of DNA, which results in cell-cycle arrest and apoptosis (Jordan and CarmoFonseca, 2000). Cell death induced by cisplatin is concentration dependent and includes necrosis and apoptosis mechanisms. Apoptosis results from activation of caspase8, caspase9, caspase 3 and caspase7 (Gonzalez et al., 2001).

The use of radio protective compounds not only protects the surrounding normal tissue but also allows the use of the effective radiation doses required for cancer control. Quinolones have been used to control chemotherapy-induced neutropenia (Freifeld et al., 1999). Also, quinolones were found to increase survival and prevent mortality of mice subjected to gamma radiation (Brook and Elliott, 1991), and mixed field radiation (Brook et al., 1993).

Ciprofloxacin, fluoroquinolone, widely used to combat bacterial infection during a national emergency such as a nuclear detonation or other radiological incident (Brook et al., 2005). Also, it was effective in management of radiation combined injury in mice through decreased interleukin- 6 concentrations, enhanced interleukin-3 production and increased red blood cell counts, haemoglobin levels, and haematocrits. Moreover, it significantly reduced both apoptotic activity and combined injury induced autophagy (Fukumoto et al., 2014

Egypt. J. Rad. Sci. Applic., Vol. 28, No. 1-2 (2015) 
and Kiang and Fukumoto, 2014). Recently, it was found to have ability to radiosensitize the tumour cells via activation of caspase-3 and inhibition of B-cell lymphoma-2 (BCL-2) production and protect normal cells via inhibition of caspase-3 and promotion of BCL-2 (Kiang et al., 2014). The aim of this work is to investigate if EHQA can ameliorate the oxidative damage occurred in the tongue after exposure to cisplatin and gamma radiation.

\section{Material and Methods}

\section{Experimental animals}

Twenty four adult male Egyptian Albino mice of comparable wt ranging from 70-100 g were used for the study. The animals were housed in especially designed cages (4mice/ cage), in a room with a 12-h light/ dark cycle, temperature of $24-28^{\circ} \mathrm{C}$, humidity of $45-64 \%$. All animals were fed with semi purified diet and water ad libitum for 10days before the start of the experiment.

\section{Irradiation}

A single dose of $2 \mathrm{~Gy}$ whole body gamma irradiation of animals was performed at NCRRT, Nasr City, Egypt, using ${ }^{137}$ Cesium gamma cell-40 giving a dose rate of $0.45 \mathrm{~Gy} / \mathrm{min}$ at time the of experiment.

\section{Cisplatin administration}

Cisplatin injected subcutaneously at dose of $(1 \mathrm{mg} / \mathrm{kg} /$ day $)$ for 5 days before irradiation. Platinol; cisplatin injection was obtained from Bristol-Myers Squibb Company.

\section{Non-fluoroquinolone administration}

Daily subcutaneous injections of EHQA $(15 \mathrm{mg} / \mathrm{kg} /$ day) for 14 days were injected to mice before irradiation.

\section{Chemistry of EHQA}

The EHQA used in this study, was prepared by oxidation of difluoroboryl complex of 3-acetylquinolinones (EAFQ), which was obtained via reaction of acetylquinolinone (EAHQ) with boron triflouride diethyl etherate, using selenium dioxide in boiling dioxane, Scheme 1. (Abass et al., 2013).

Egypt. J. Rad. Sci. Applic., Vol. 28, No. 1-2 (2015) 


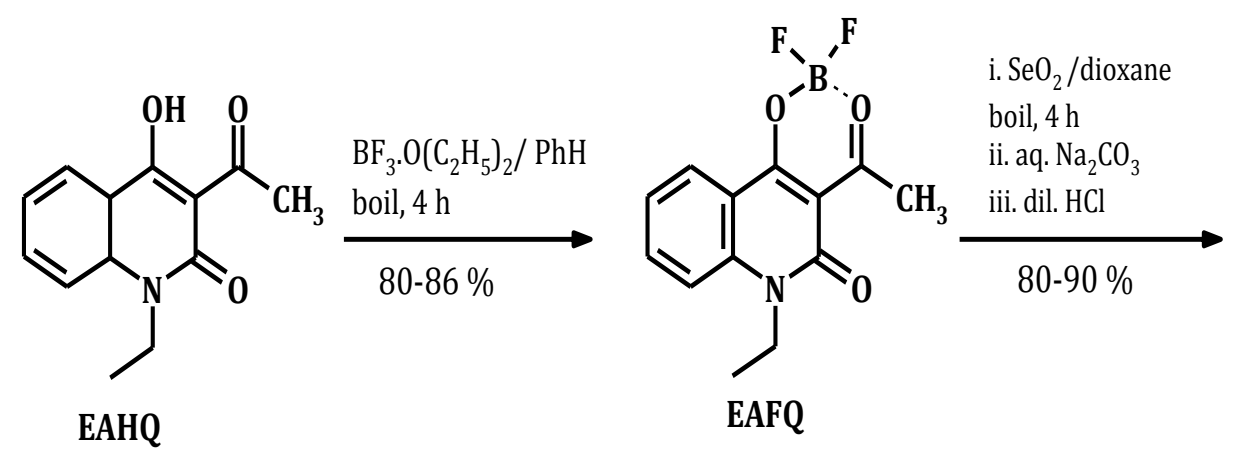<smiles>O=C(O)C(=O)c1c(O)c2ccccc2n(CCO)c1=O</smiles>

Scheme 1. Synthesis of EHQA.

\section{Experimental design}

Mice were randomly divided into 4groups: Group C: Mice were served as control group. Group SR: Mice were injected with cisplatin and irradiated on the last day. Group QSR: Mice were injected with EHQA alone for 10days then in combination with cisplatin for another 5days and irradiated on the last day. Group Q: Mice were injected with EHQA only.

\section{Specimen collection and preparation}

Three days after irradiation animals were sacrificed by cervical decapitation and tongues harvested, immediately fixed in $10 \%$ formalin. Fixed specimens were dehydrated in ascending grades of ethyl alcohol, cleared in xylol, and then embedded in paraffin.

\section{Haematoxylin and eosin staining $(H \& E)$}

Five microns thick paraffin sections were cut. The prepared sections were stained by Harris's H\&E, for histological evaluation of any structural changes in the tongues.

Egypt. J. Rad. Sci. Applic., Vol. 28, No. 1-2 (2015) 


\section{Immune histo-chemical staining}

Bcl-2\&Ki-67 (A proliferative-associated antigen) were used. Four to five microns thick sections were cut on tissue adhesive coated slides. Bcl-2 was used to detect apoptosis while Ki-67 was used for detection of proliferative activity.

\section{Evaluation of staining}

All slides were examined with light microscopy for histological evaluation of the H\&E stained sections and detection of the specific brown reaction product of the 3,3, diaminobenzidine (DAB) substrate in the immune stained sections. Immune reactivity for $\mathrm{Bcl}-2$ and $\mathrm{Ki}-67$ was done by the aid of an image analyser computer system using the software Leica Qwin 500. Five representative areas of each stained slide were observed under high power (X 400) using a light microscope. Areas of the most intense immune stained tissue were chosen for measurement of area and area present.

\section{Statistical evaluation}

The measured values were expressed as mean values \pm S. D. (standard deviation). The statistical importance of the difference in these values between different groups was estimated using Student's $t$-test. A $p$-value less than 0.05 were considered significant and value less than 0.01 were considered highly significant.

\section{Results}

\section{H\&E-findings}

Group C: The tongue of the control group revealed keratinized stratified squamous epithelium of normal thickness, architecture and keratinization with intact basement membrane. The lamina propria of dense connective tissue contained normal fibroblasts, collagen fibres and blood vessels. The sub mucosa demonstrated normal muscle bundles. The dorsal surface showed normal cone shaped filiform papillae (Fig. 1A).

Group SR: Histological examination of tongue tissue revealed some atrophied tongue papillae and desquamated keratin layer. The basal cells of the stratified squamous epithelium showed irregular alignment, hyper chromatic nuclei. Increased mitotic figure was detected in both basal and granular cells.

Egypt. J. Rad. Sci. Applic., Vol. 28, No. 1-2 (2015) 
Some of the granular cells showed vacuolization. The basement membrane was intact but irregular. Area of muscular degeneration was detected in the sub mucosa (Fig. 1B).
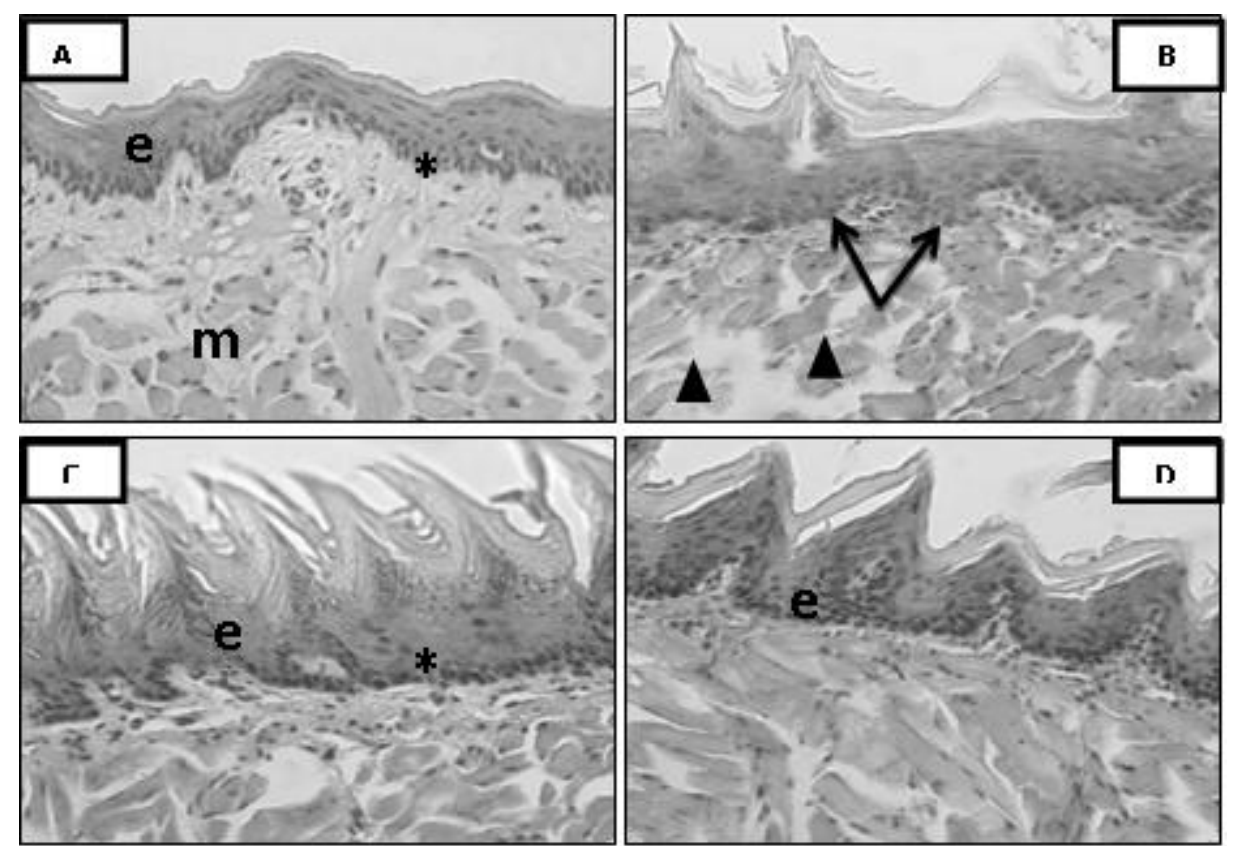

Fig. 1. Photomicrograph of tongue tissue of $A$ group $C$, showing normal histological appearance of keratinized stratified squamous epithelium (e), intact basement membrane (asterisks). Normal muscle (m), B, group SR showing irregular basement membrane with irregularly aligned basal cells (arrows), degenerated muscle (arrowheads); C, group QSR showing normal epithelium (e), intact basement membrane (asterisks); D, group Q showing normal epithelium (e). [H\&Ex400]

Group QSR: This group revealed area of hyperkeratinisation with normal basal and granular cells. Intact, regular basement membrane was detected. The tongue papillae were of normal thickness and keratinization. The connective tissue demonstrated normal fibroblast, collagen fibres and blood vessels. The muscle of the sub mucosa was normal (Fig. 1C).

Group Q: The epithelium of this group revealed normal thickness and keratinization. Increased mitosis was obvious in basal and granular cells. The basement membrane was intact and regular. Less degeneration was detected in the muscles of the sub mucosa (Fig. 1D).

Egypt. J. Rad. Sci. Applic., Vol. 28, No. 1-2 (2015) 


\section{Bcl-2 findings}

Immune histo-chemical examination of tongue of group $\mathrm{C}$ revealed mild reaction in few epithelial and connective tissue cells (Fig. 2A). Negative Bcl-2 immunoreaction was detected in both epithelial and connective tissue cells of the group SR (Fig. 2B). In group QSR, the strongest immune staining was detected in the basal cells of the epithelium while cells of the connective tissue expressed moderate reaction (Fig. 2C). The epithelium of group Q showed weak to moderate reaction in few cells along the epithelium but cells of the connective tissue showed moderate to intense reaction (Fig. 2D). The Image Analysis of Bcl-2 stained tongue tissues showed non-significant decrease in the mean area per cent in the group SR $(1.29 \pm 0.43)$ as compared to the group C (2.35 \pm 0.73$)$. Group QSR (17.79 \pm 3.09$)$ revealed highly significant increase as compared to C group. The mean area per cent of group Q $(25.94 \pm 3.97)$ was higher than all groups and this difference was highly significant (Fig. 3).
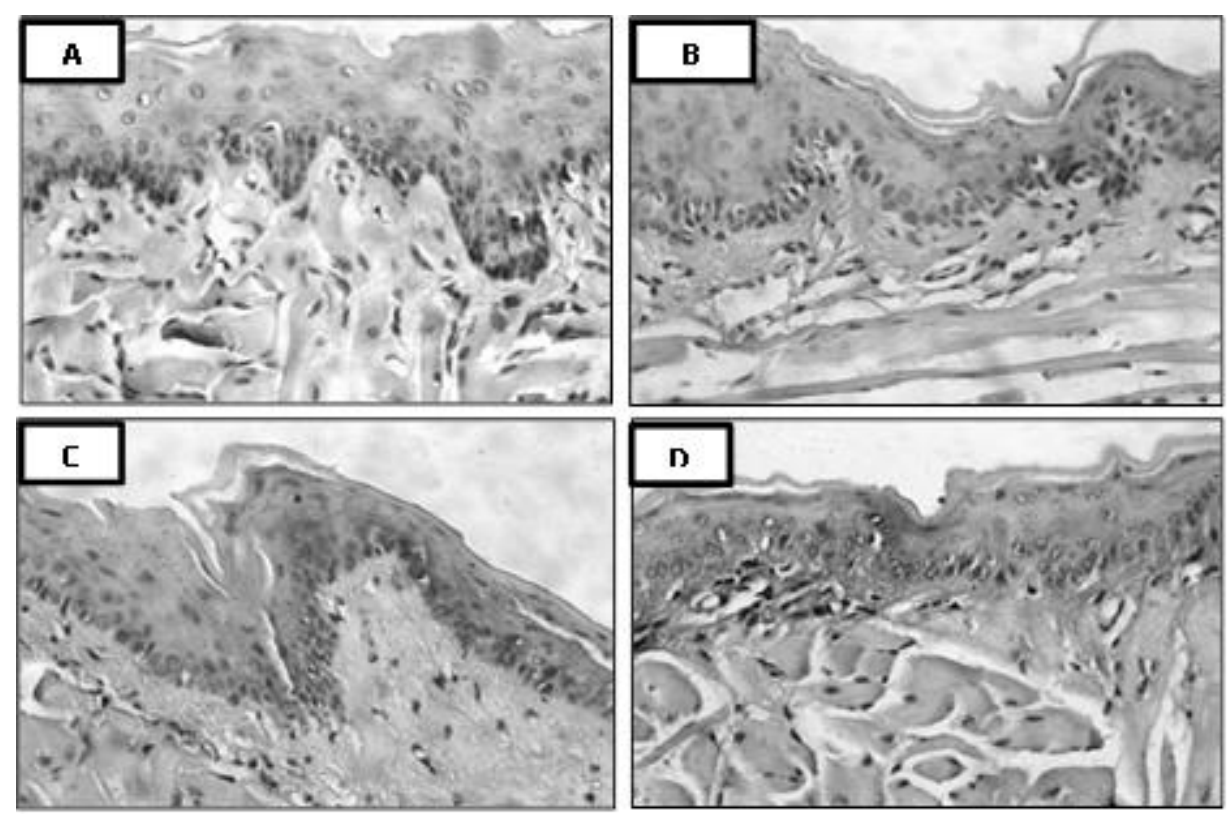

Fig. 2. Photomicrograph of Bcl-2 expression of $\mathrm{A}$ group $\mathrm{C}$, showing weak reaction in epithelial and connective tissue cells; B, group SR showing rare very mild all over the epithelium and connective tissue; C, group QSR showing intense reaction in the basal cells and moderate reaction in the connective tissue components; D, group $Q$ showing intense reaction in connective tissue and weak reaction in few epithelial cells. [Bcl-2x400]

Egypt. J. Rad. Sci. Applic., Vol. 28, No. 1-2 (2015) 


\section{Ki-67 findings}

Moderate immune reactivity for Ki-67 was detected in the basal and suprabasal cells of group $\mathrm{C}$ epithelium, while, mild immunoreaction was detected in the most superficial cell layer. In group SR, very mild reaction was detected in few cells of all layers of the epithelium and connective tissue. Both group QSR and Q revealed intense reaction to $\mathrm{Ki}-67$ with most reaction in the basal cell layer that was higher in group Q. The mean Ki-67 area per cent of the control tongue $(9.29 \pm 3.05)$ was moderate. Marked significant decrease in the area per cent was detected in group SR $(3.87 \pm 0.27)$ as compared to the control. The increase in the area per cent of group QSR (21.89 \pm 3.13$)$ was highly significant in comparison to the control. Group Q (15.76 \pm 2.46$)$ showed significant increase in the area per cent as compared to the control (Fig. 3).

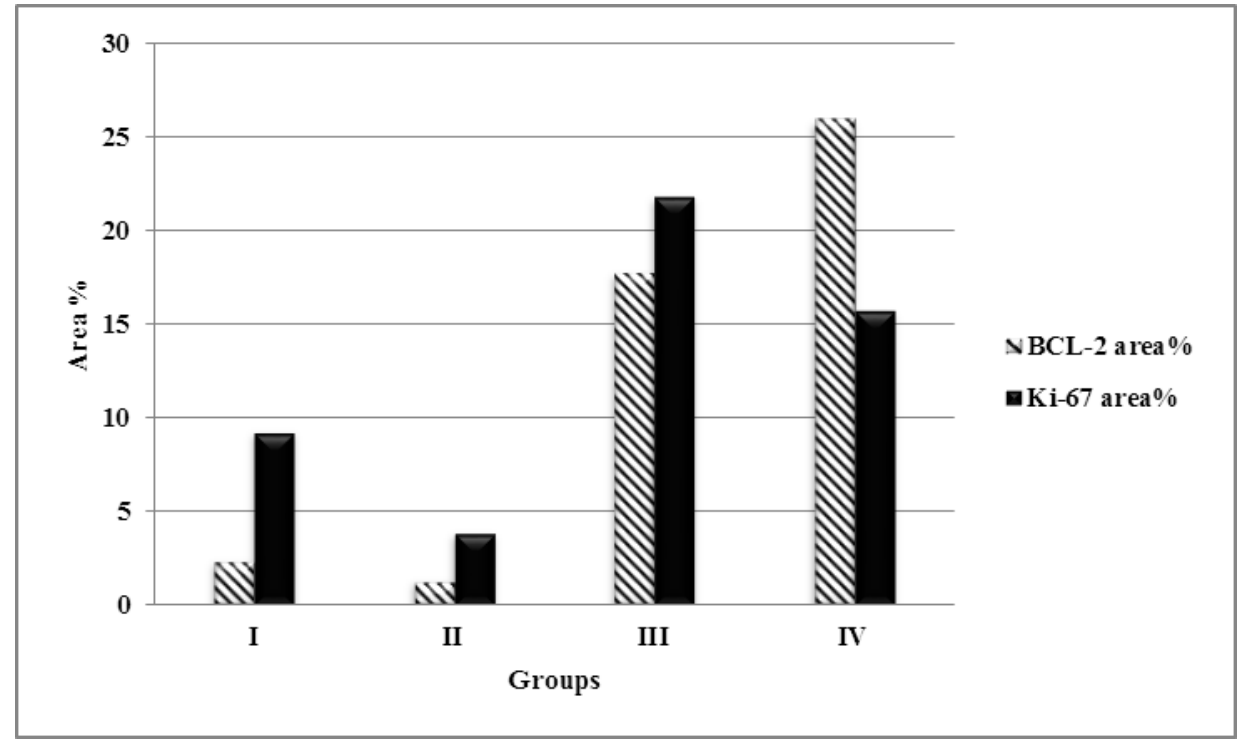

Fig. 3. A histogram representing the area \% of Bcl-2\&Ki-67 expression in the tongue of different experimental groups.

\section{Discussion}

Cisplatin an alkylating agent is one of the chemotherapeutic agents that effectively treat various types of cancer including testicular, lung, ovarian and head and neck cancer (Kelland, 2007). Oral mucositis is a common side effect of using cytotoxic chemotherapy to treat most cancers and, in particular, of Egypt. J. Rad. Sci. Applic., Vol. 28, No. 1-2 (2015) 
radiation therapy with or without chemotherapy for head and neck cancers. It reduces patient quality of life, affects nutritional intake, leads to oral and systemic infections, as well as limits therapy (Elting et al., 2008). Till now there is no radio-protector that can significantly reduce oral mucositis, therefore, there is a need for different agents that may prevent or even reduce oral mucositis development during cancer therapy.

Histological examination of cisplatin-gamma irradiated tongue revealed some atrophied tongue papillae and desquamated keratin layer. This was in accordance with the finding of Mazzeo et al. (2009). Some sections showed irregularly aligned basal cells with hyper chromatic nuclei. Increased mitotic figure was detected in both basal and granular cells. Some of the granular cells showed vacuolization. The basement membrane was intact but irregular with area of muscular degeneration in the sub mucosa. These results were in accordance with those obtained by Chen et al., (2004). These findings were explained by Nguyen et al., (2012) who reported that irradiation mainly affect the taste progenitor cell that suffered from cell cycle arrest and apoptosis in the first days after irradiation.

Results from Bcl-2 and Ki-67 immune-histo-chemical staining showed decreased expression of both markers that may explain the histological finding. Similar results were obtained by Abd El-Hamid et al. (2011) who found that use of chemotherapeutic drugs resulted in negative proliferating cell nuclear antigen (PCNA) and Bcl-2 immune expression in all epithelial layers. Decreased Bcl-2 immune expression and increased apoptotic activity were explained by Hengartner, (2000) who stated that chemotherapeutic drugs activates the sensors of damage that antagonizes the anti-apoptotic proteins and activates proapoptotic proteins, which form channels in the mitochondrial membranes allowing the release of cytochrome-c in the cytoplasm which activates caspases ending with apoptosis and Belikova et al. (2009) who attributed irradiation induced apoptosis to caspase-3 and 7 activation. While, decreased Ki-67 expression can be attributed to inhibition of DNA and RNA synthesis following chemotherapy and / irradiation leading to cell cycle arrest (De- Angelis et al., 2006). In the current study, administration of EHQA before receiving cisplatin and gamma radiation reduced their harmful effects on the tongue. This was manifested by normal basal and granular cells, Intact and regular basement 
membrane. Also, the connective tissue demonstrated normal fibroblast, collagen fibres and blood vessels with normal muscle of the sub mucosa. Bcl-2\&Ki-67 expression revealed noticeable increase in anti-apoptotic protein expression with marked enhancement of cell proliferation which may explain the histological findings. However, no researches focused on the effect of fluoroquinolone or non-fluoroquinolone on the proliferative cell capacity but many researchers found that fluoroquinolone increased erythropoiesis (Fukumoto et al., 2014). Regarding the apoptotic process, fluoroquinolone treatment significantly reduced numbers of apoptotic cells and this was attributed to decreased caspase-3 activity (Fukumoto et al., 2013) and promotion of Bcl-2 (Kiang et al., 2014).

\section{Conclusion}

In this Vivo experiment the administration of EHQA inhibited the oxidative stress induced by cisplatin and gamma radiation. The mechanism by which EHQA exerted its effect may be due to up regulation of anti-apoptotic factors and enhancement of cell proliferative capacity.

\section{Acknowledgment}

Great attitude and appreciation are for Dr. Heba Hassan Ibrahim, Chemistry Dept., Faculty of Education, Ain Shams University, Egypt for her effort in preparing the new compound under investigation.

\section{References}

Abass, M., Allimony, H. A. and Heba, H. (2013) Substituted quinolinones. Part 19. New and unexpected results from oxidation of 3-acetyl-1-alkyl-4hydroxyquinolin-2(1H)-ones using selenium dioxide. Phosphorus, Sulfur. Silicon. Related Elements, 188, 1799.

Abd El-Hamid, A., Khater, D. and Abd El-Latif, M. (2011) The effect of methotrexate and 5-Fluorouracil on various oral tissues: An experimental study. Egypt. Dent. J., 57, 2541.

Baliga, M. S. and Rao, S. (2010) Radioprotective potential of mint: A brief review. $J$. Cancer Res. Ther., 6, 255.

Belikova, N., Jianga, J., Stoyanovskyb, D., Glumaca, A., Bayira, H., Greenbergere, J. and Kagana, V. (2009) Mitochondria-targeted (2-hydroxyamino-vinyl)triphenyl-phosphonium releases $\mathrm{NO}$ and protects mouse embryonic cells against irradiation-induced apoptosis. FEBS Letters, 583, 1945.

Egypt. J. Rad. Sci. Applic., Vol. 28, No. 1-2 (2015) 
Brook, I. and Elliott, T. B. (1991) Quinolone therapy in the prevention of mortality after irradiation. Radiat. Res., 128, 100.

Brook, I., Germana, A., Giraldo, D. E., Camp-Hyde, T. D., Bolduc, D. L., Foriska, M. A., Elliott, T. B., Thakar, J. H., Shoemaker, M. O., Jackson, W. E. and Ledney, G. D. (2005) Clindamycin and quinolone therapy for Bacillus anthracis Sterne infection in ${ }^{60}$ Co-gamma-photon-irradiated and shamirradiated mice. J. Antimicrob. Chemother., 56, 1074.

Brook, I., Tom, S. and Ledney, G. D. (1993) Quinolone and glycopeptide therapy for infection in mouse following exposure to mixed-field neutron- $\gamma$-photon radiation. Int. J. Radiat. Biol., 64, 771.

Chen, N., Zhao, S. F., Gu, Z. Y., Zhang, Y. Q. and Zhang, N. G. (2004) Changes of taste bud and fungiform papillae after $60 \mathrm{Co}$ radiation in rat. Hua Xi Kou Qiang Yi Xue Za Zhi, 22, 510.

Cotrim, A. P., Yoshikawa, M., Sunshine, A. N., Zheng, C., Sowers, A. L., Thetford, A. D., Cook, J. A., Mitchell, J. B. and Baum, B. J. (2012) Pharmacological protection from radiation \pm Cisplatin - induced oral mucositis. Int. J. Radiat. Oncol. Biol. Phys., 83, 1284.

De-Angelis, P. M., Svendsrud, D. H., Kravik, K. L. and Stokke, T. (2006) cellular response to 5-fluorouracil (5-FU) in 5-FU resistant colon cancer cell lines during treatment and recovery. Mol. Cancer, 18, 5 .

Elting, L. S., Keefe, D. M., Sonis, S. T., Garden, A. S., Spijkervet, F. K., Barasch, A., Tishler, R. B., Canty, T. P., Kudrimoti, M. K. and Vera-Llonch, M. (2008) Patient-reported measurements of oral mucositis in head and neck cancer patients treated with radiotherapy with and without chemotherapy: demonstration of increased frequency, severity, resistance to palliation, and impact on quality of life. Cancer, 113, 2704.

Freifeld, A., Marchigiani, D., Walsh, T., Chanock, S., Lewis, L., Hiemenz, J., Hiemenz, S., Hicks, J. E., Gill, V., Steinberg, S. M. and Pizzo, P. A. (1999) A double-blind comparison of empirical oral and intravenous antibiotic therapy for low-risk febrile patients with neutropenia during cancer chemotherapy. N. Engl. J. Med., 341, 305.

Fukumoto, R., Burns, T. M. and Kiang, J. G. (2014) Ciprofloxacin enhances stress erythropoiesis in spleen and increases survival after whole-body irradiation combined with skin-wound trauma. PLoS One, 9, e90448.

Fukumoto, R., Cary, L., Gorbunov, N., Lombardini, E., Elliott, T. and Kiang, J. G. (2013) Ciprofloxacin modulates cytokine/chemokine profile in serum, improves bone marrow repopulation, and limits apoptosis and autophagy in ileum after whole body ionizing irradiation combined with skin-wound trauma. PLoS One., 8, e58389.

Gonzalez, V. M., Fuertes, M. A., Alonso, C. and Perez, J. M. (2001) Is cisplatininduced cell death always produced by apoptosis?. Mol. Pharmacol., 59, 657.

Hengartner, M. O. (2000) The biochemistry of apoptosis. Nature, 407, 770.

Egypt. J. Rad. Sci. Applic., Vol. 28, No. 1-2 (2015) 
Hogle, W. P. (2007) Cytoprotective agents used in the treatment of patients with cancer. Semin. Oncol. Nurs., 23, 213.

Hosseinimehr. S. J. (2007) Trends in the development of radioprotective agents. Drug Dis. Today, 12, 794.

Jordan, P. and Carmo-Fonseca, M. (2000) Molecular mechanisms involved in cisplatin cytotoxicity. Cell. Mol. Life Sci., 57, 1229.

Kelland, L. (2007) The resurgence of platinum-based cancer chemotherapy. Nat. Rev. Cancer, 7, 573.

Kiang, J. G. and Fukumoto, R. (2014) Ciprofloxacin increases survival after ionizing irradiation combined injury: $\gamma-\mathrm{H} 2 \mathrm{AX}$ formation, cytokine/chemokine, and red blood cells. Health Phys., 106, 720.

Kiang, J. G., Garrison, B. R., Smith, J. T. and Fukumoto, R. (2014) Ciprofloxacin as a potential radio-sensitizer to tumor cells and a radio-protectant for normal cells: differential effects on $\gamma$-H2AX formation, p53 phosphorylation, Bcl-2 production, and cell death. Mol. Cell Biochem., 393, 133.

Mazzeo, M. A., Linares, J. A., Campos, M. L., Busamia, B. E., Dubersarsky, C., Lavarda, M., Jarchum, G. and Finkelberg, A. B. (2009) Oral sign of intravenous chemotherapy with 5- Fluorouracil and Leucovorin calcium in colon cancer reatment. Med. Oral Patol. Oral Cir. Bucal., 14, E108.

Nguyen, H. M., Reyland, M. E. and Barlow, L. A. (2012) Mechanisms of taste bud cell loss after head and neck irradiation. J. Neurosci., 32, 3474.

Siddik, Z. H. (2003) Cisplatin: mode of cytotoxic action and molecular basis of resistance. Oncogene, 22, 7265.

Treister, N. and Sonis, S. (2007) Mucositis: biology and management. Curr. Opin. Otolaryngol. Head Neck Surg., 15, 123.

(Received: 30/08/2015;

accepted: 25/10/2015)

Egypt. J. Rad. Sci. Applic., Vol. 28, No. 1-2 (2015) 


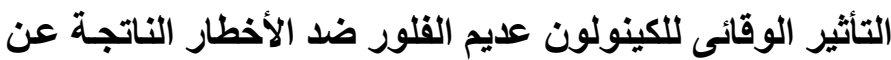

$$
\begin{aligned}
& \text { العلاج الكيماوى و الإشعاعى فى الفئران البيضاء الصغئ الصغيرة } \\
& \text { سلوى فريد أحمد ، و محمد عباس عبد الرحمن* }
\end{aligned}
$$

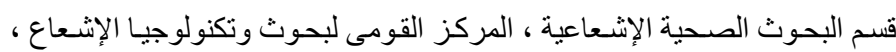

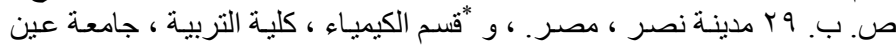

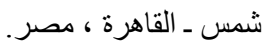

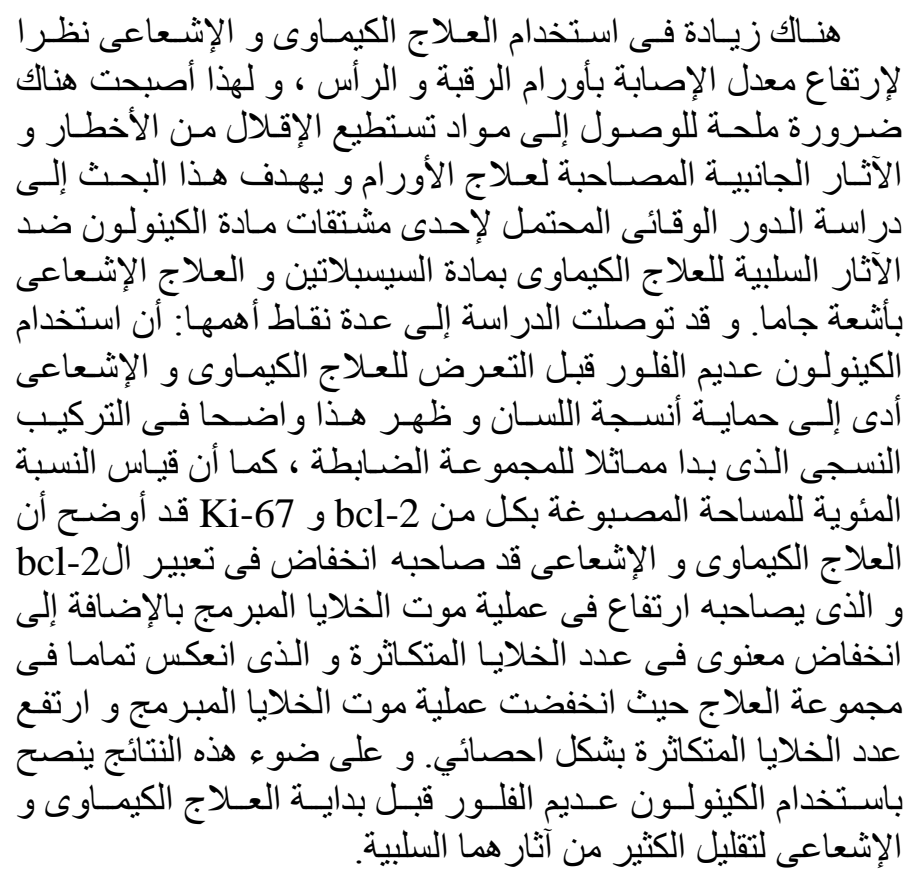

Egypt. J. Rad. Sci. Applic., Vol. 28, No. 1-2 (2015) 